\title{
Fermentative production of the unnatural amino acid L-2-aminobutyric acid based on metabolic engineering
}

\author{
Jian-Miao Xu, Jian-Qiang Li, Bo Zhang, Zhi-Qiang Liu* (1) and Yu-Guo Zheng
}

\begin{abstract}
Background: $L-2$-aminobutyric acid ( $L-A B A)$ is an unnatural amino acid that is a key intermediate for the synthesis of several important pharmaceuticals. To make the biosynthesis of L-ABA environmental friendly and more suitable for the industrial-scale production. We expand the nature metabolic network of Escherichia coli using metabolic engineering approach for the production of L-ABA.

Results: In this study, Escherichia coli THR strain with a modified pathway for threonine-hyperproduction was engineered via deletion of the rhtA gene from the chromosome. To redirect carbon flux from 2-ketobutyrate (2-KB) to L-ABA, the ilVIH gene was deleted to block the L-isoleucine pathway. Furthermore, the ilvA gene from Escherichia coli W3110 and the leuDH gene from Thermoactinomyces intermedius were amplified and co-overexpressed. The promoter was altered to regulate the expression strength of $i l v A^{*}$ and leuDH. The final engineered strain $E$. coli THR $\triangle r h t A \triangle i l v I H /$ Gap-ilvA*-Pbs-leuDH was able to produce $9.33 \mathrm{~g} / \mathrm{L}$ of L-ABA with a yield of $0.19 \mathrm{~g} / \mathrm{L} / \mathrm{h}$ by fed-batch fermentation in a $5 \mathrm{~L}$ bioreactor.
\end{abstract}

Conclusions: This novel metabolically tailored strain offers a promising approach to fulfill industrial requirements for production of L-ABA.

Keywords: L-2-Aminobutyric acid, L-Threonine deaminase, L-Leucine dehydrogenase, Metabolic engineering, Fedbatch fermentation

\section{Background}

L-2-aminobutyric acid (L-ABA), a nonnatural amino acid, has been used as a precursor for synthesis of many chiral drugs, such as anti-epileptic Levetiracetam, anti-tuberculotic Ethambutol and Brivaracetam [1-3]. (S)-2-amino butanol, a key intermediate of Ethambutol, can be synthesized by esterification and hydrogenation reduction of L-ABA [4]. With the increasing market demand for $\mathrm{L}-\mathrm{ABA}$ in both pharmaceutical and chemical industries in recent years, the preparation of optically pure L-ABA with high efficacy has attracted much attention.

Currently, the preparation of L-ABA is mainly achieved by chemical synthesis or enzymatic conversion. In

\footnotetext{
*Correspondence: microliu@zjut.edu.cn
}

Key Laboratory of Bioorganic Synthesis of Zhejiang Province, College of Biotechnology and Bioengineering, Zhejiang University of Technology, Hangzhou 310014, China chemical methods, synthesis of L-ABA has been extensively reported including ammonolysis of $\alpha$-halogen acid [5], reduction reaction [6], ammoniation hydrolysis reaction and butanone acid reduction [7]. However, the obvious disadvantages of chemical synthesis, such as poor selectivity, harsh reaction conditions, various byproducts, and the difficulty in separation and purification [8-10], limited its development. Enzymatic synthesis of L-ABA is emerged since biotransformation and bio-refining for the green production of chemicals have been attracting the increasing attention due to serious concerns about climate change and environmental problems [11-13]. It is reported that L-ABA was synthesized in a transamination reaction from $\alpha$-ketobutyric acid and L-aspartic acid as substrates using aromatic aminotransferase [14] or produced from $\alpha$-ketobutyric acid and benzylamine using $\omega$-aminotransferase [1]. L-ABA could also be produced 
from the reduction of $\alpha$-keto acids with L-leucine dehydrogenase [15] or glutamate dehydrogenase [16]. But in the enzymatic routes, the presence of by-product $\alpha$-keto acid decreases the overall yield and purity of L-ABA [2]. It is well known that, most of the natural L-amino acids can now be produced from glucose by microbial fermentation [17]. Notably, L-glutamate, L-lysine, and L-threonine are produced more than 2 million tons annually [18]. Therefore, microbial production of L-ABA from cheap and clean resources has gained much attention with the potential to overcome these problems.

Escherichia coli has been reported to produce many natural amino acids owing to its clear genetic background and facile genetic manipulation $[17,19]$. At present, there are few reports about biosynthesis of the nonnatural amino acid L-ABA using microbial fermentation. We attempt to construct a novel engineered $E$. coli strain for production of the nonnatural amino acid, L-ABA directly from glucose by expanding its metabolic pathways.

In this study, a threonine producing strain $E$. coli THR was firstly constructed, then the metabolic pathway was expanded via specific genes overexpression for converting L-threonine to L-ABA. Further modification for improvement of L-ABA production included L-threonine reduction, $\mathrm{L}$-isoleucine synthetic pathway blockage and promoter replacement. This work provides a novel approach for the industrial production of L-ABA by fermentation using the genetically engineered $E$. coli strain.

\section{Results}

\section{Construction of engineered $E$. coli strain for L-threonine production}

To expand metabolism for producing L-ABA, we designed a unique metabolic pathway in E. coli, where L-threonine was taken as a precursor for L-ABA synthesis (Fig. 1). In this work, E. coli THR strain (Table 1) was constructed for the overproduction of L-threonine. The feedback inhibitions of aspartokinase I and III encoded by $t h r A$ and $l y s C$ genes, respectively, were released [20]. The native promoter containing the transcriptional attenuator leader region of the $\operatorname{th} A B C$ operon was replaced with the tac promoter. The metA, lys $A, t d h$ and $i c l R$

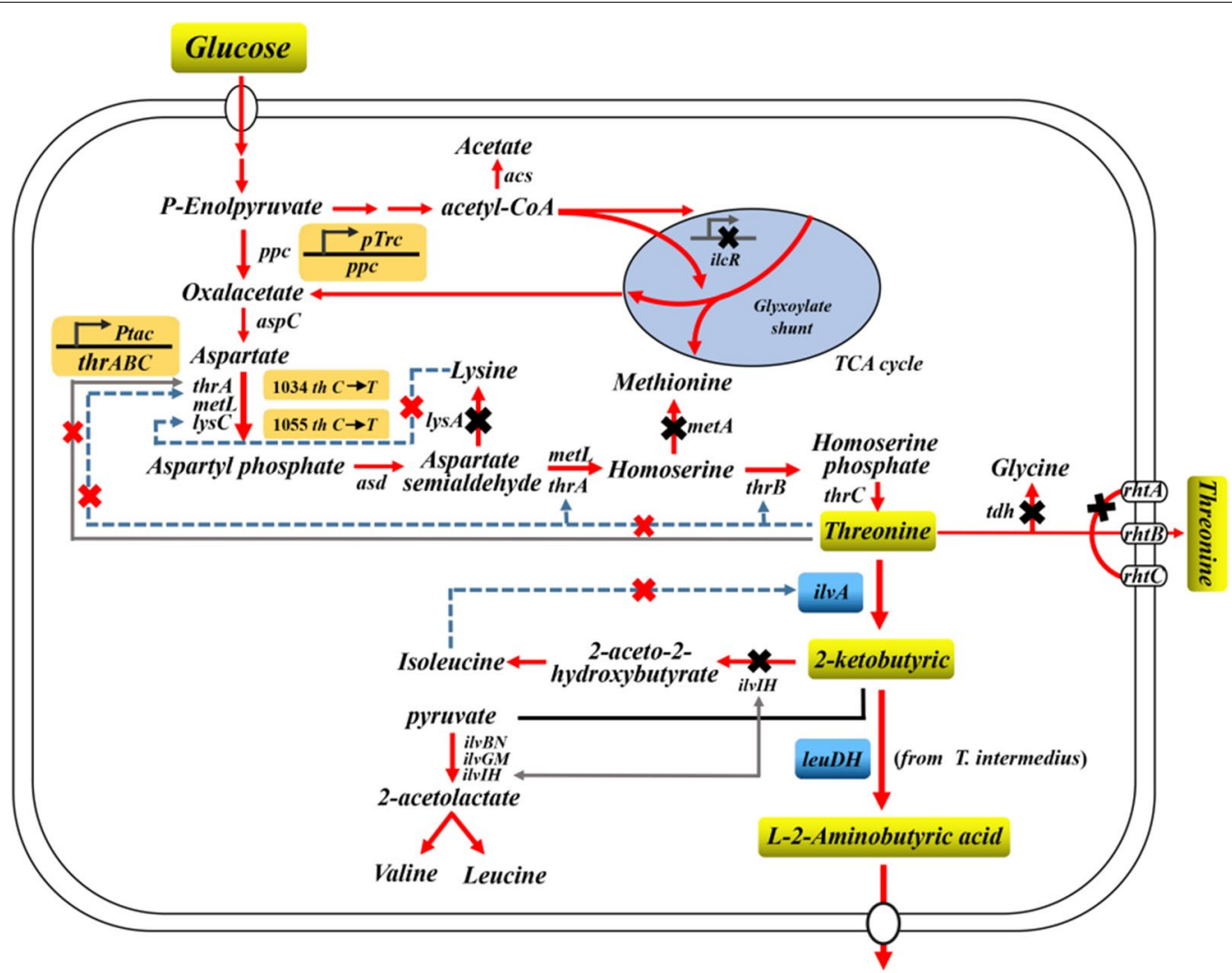

Fig. 1 The overall metabolic engineering strategy employed for the construction of a genetically defined L-ABA producer. Central metabolic pathways that contribute to the biosynthesis of L-ABA together with competing pathways and regulatory circuits are shown. The orange shaded boxes represent mutations introduced into the genome. The black Xs indicate the deletion of genes and the red Xs indicate the removal of inhibition or repression. Dotted lines indicate the feedback inhibition. Gray lines indicate the transcriptional attenuation regulation. The red thick arrows indicate the increased flux or activity by directly overexpressing the corresponding genes 
Table 1 Characteristics and sources of bacterial strains used in this study

\begin{tabular}{|c|c|c|}
\hline Strains & Characteristics & Sources \\
\hline E. coliW3110 & Coli Genetic Stock Center strain (CGSC) No. 4474 & CGSC $^{a}$ \\
\hline E. coli TOP10 & $\begin{array}{l}\mathrm{F}^{-} \text {mcrA } \triangle(\text { mrr-hsdRMS-mcrBC) } \varphi 80 \text { lacZ } \triangle M 15 \triangle \text { lacX74 deoR recA1 araD139 } \triangle \text { (ara-leu)7697galU galK } \\
\quad \text { rpsL endA1 nupG }\end{array}$ & Invitrogen ${ }^{b}$ \\
\hline E. coliTHR & 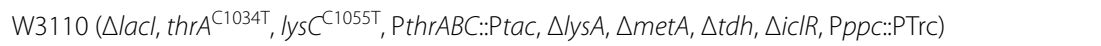 & This study \\
\hline E. coliTHR $\triangle r h t A$ & E. coliTHR derivative, $\triangle r h t A$ & This study \\
\hline E. coliTHR $\triangle r h t C$ & E. coli THR derivative, $\triangle r h t C$ & This study \\
\hline E. coli THR $\triangle r h t A \Delta r h t C$ & E. coli THR derivative, $\Delta r h t A / \Delta r h t C$ & This study \\
\hline E. coliTHR $\triangle r h t A \triangle i l v I H$ & E. coliTHR derivative, $\triangle r h t A / \triangle i l v I H$ & This study \\
\hline
\end{tabular}

a Invitrogen, Crop., Carlsbad, CA

b Coli Genetic Stock Center

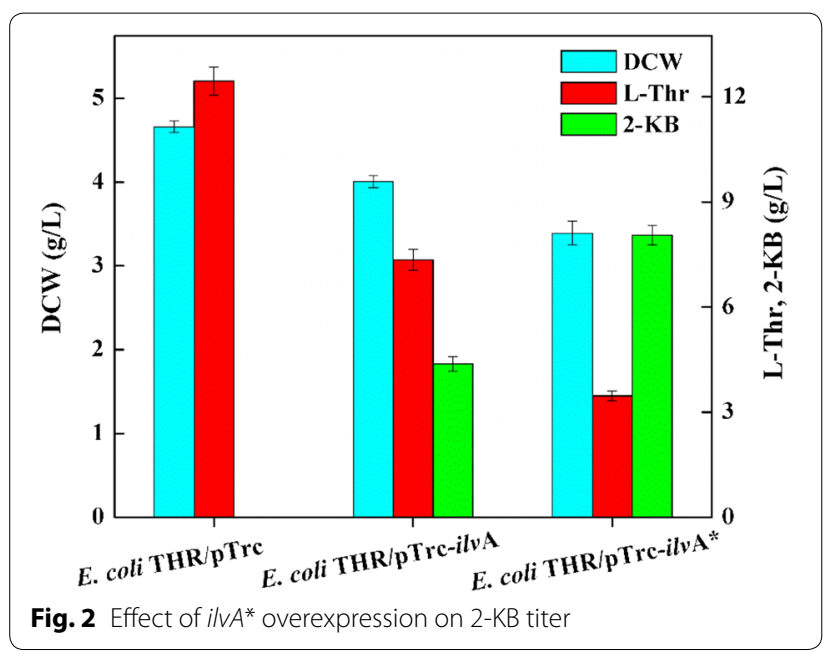

genes were deleted to make more precursors available for $\mathrm{L}$-threonine formation. The native promoter of the $p p c$ gene was replaced with the Trc promoter in the chromosome to increase the pool of oxaloacetate, a starting precursor of L-threonine biosynthesis [21]. As a result, the strain E. coli THR produced $12.45 \mathrm{~g} / \mathrm{L} \mathrm{L}$-threonine from $50 \mathrm{~g} / \mathrm{L}$ glucose in shake flask at $35^{\circ} \mathrm{C}$ for $48 \mathrm{~h}$ in TPM medium, which was further used to construct an L-ABA producing strain.

\section{Reprogramming of ilvA to redirect the carbon flux towards 2-KB}

It is well known that L-threonine was catalyzed to form $2-\mathrm{KB}$ by threonine dehydratase encoded by $i l v A$ in $E$. coli. In this study, an $i l v A$ overexpression strain was constructed, which could produce $4.38 \mathrm{~g} / \mathrm{L} 2-\mathrm{KB}$ and $7.35 \mathrm{~g} / \mathrm{L}$ L-threonine (Fig. 2). The high accumulation of L-threonine intracellularly indicated that the catabolic enzyme $i l v A$ is not active enough to fully convert $\mathrm{L}$-threonine into 2 -KB. The feedback inhibition of $i l v A$ by L-isoleucine was then considered as the main factor to hinder the further improvement of the 2-KB titer [16].

On the basis of previous studies, feedback inhibition of $i l v A$ could be removed by replacing the 1054 th $\mathrm{T}$ with G, 1055 th T with C, 1084 th C with T, 1085 th G with T and 1086 th $\mathrm{T}$ with $\mathrm{C}$ (F352A, R362F) using site-directed mutagenesis to obtain pTrc-ilvA* [22]. The 2-KB titer of E. coli THR/pTrc-ilvA* increased by $83.8 \%$ which was up to $8.05 \mathrm{~g} / \mathrm{L}$, the value of which was nearly 2 times of that from the pTrc-ilvA strain $(4.38 \mathrm{~g} / \mathrm{L} \mathrm{2-KB})$, and the concentration of remaining L-threonine from $7.35 \mathrm{~g} / \mathrm{L}$ decrease to $3.47 \mathrm{~g} / \mathrm{L}$ (Fig. 2). These results suggested that the removal of $\mathrm{L}$-isoleucine which is the feedback inhibition of the $i l v A$ gene could increase both the activity and resistance to $\mathrm{L}$-isoleucine inhibition as compared to that of the wild-type strain and drive the carbon flux from L-threonine to 2-KB [22].

\section{Enzyme selection for converting 2-KB to L-ABA}

In order to gain an appropriate dehydrogenase for $2-\mathrm{KB}$ production, two different sources of dehydrogenase, including leuDH from T. intermedius [23] and BleuDH from Bacillus cereus [24] were tested. Plasmids pTrc-leuDH and pTrc-BleuDH were constructed and introduced into $E$. coli THR. Results showed that the accumulation of $\mathrm{L}-\mathrm{ABA}$ reached to $5.39 \mathrm{~g} / \mathrm{L}$ and $3.16 \mathrm{~g} / \mathrm{L}$ in $E$. coli THR/pTrc-leuDH and E. coli THR/pTrc$B l e u D H$, respectively, which were cultivated in TPM medium with additional feeding of $10 \mathrm{~g} / \mathrm{L} \mathrm{2-KB} \mathrm{(Fig.} \mathrm{3).}$ These results demonstrated that the dehydrogenase leuDH from $T$. intermedius displayed a higher specific activity in E. coli THR than that of BleuDH from Bacillus cereus.

\section{Modification of bypass pathway to further improve the L-ABA titer \\ Based on the fermentation results from $i l v A^{*}$ and leuDH expression separately in $E$. coli THR, the}




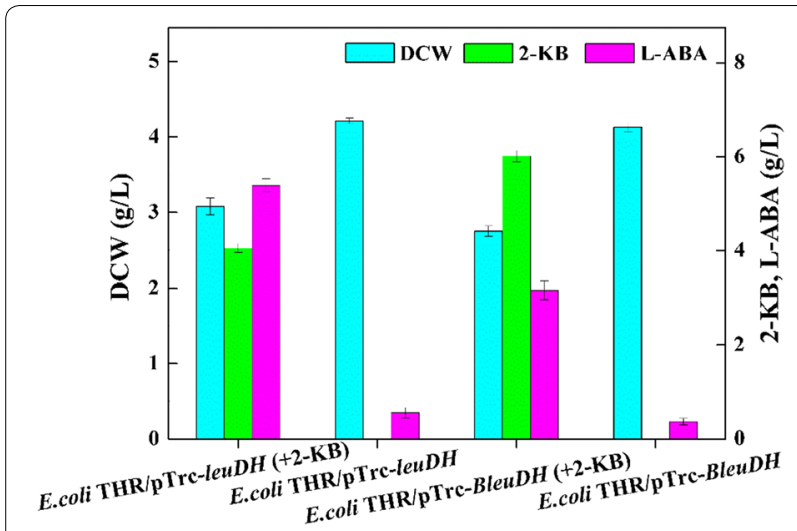

Fig. 3 Effects of leuDH and BleuDH overexpression on L-ABA titer

co-overexpression strain E. coli THR/pTrc-ilvA*-leuDH was constructed, which could produce $3.09 \mathrm{~g} / \mathrm{L}$ L-ABA from $50 \mathrm{~g} / \mathrm{L}$ glucose. However, there was still $3.47 \mathrm{~g} / \mathrm{L}$ L-threonine remained in the fermentation medium (Fig. 4). In E. coli, rht $A$ and $r h t C$ are known to be involved in L-threonine efflux $[25,26]$. When the $r h t A$ gene was overexpressed on multicopy plasmids, the expression of the $r h t A$ gene enhanced about tenfold [27]. The $r h t C$ gene was induced to protect cells from toxic effects of intracellular L-threonine accumulation by exporting L-threonine out of the cell. It is reported that overexpression of the $r h t C$ gene could increase the production of L-threonine which is $50.2 \%$ higher than that without $r h t C$ amplification [21].

With the purpose of decreasing the L-threonine export capacity, the gene $r h t A$ and $r h t C$ were deleted from the E. coli THR strain chromosome, resulting in three strains E. coli THR $\Delta r h t A, E$. coli THR $\Delta r h t C$ and E. coli THR $\Delta r h t A \Delta r h t C$. Then the recombinant plasmid pTrc-ilvA*$l e u D H$ was respectively transformed into three strains to test the L-ABA production. The result of strain $E$. coli THR $\Delta r h t A / \mathrm{pTrc}-i l v A^{*}$-leuDH displayed higher

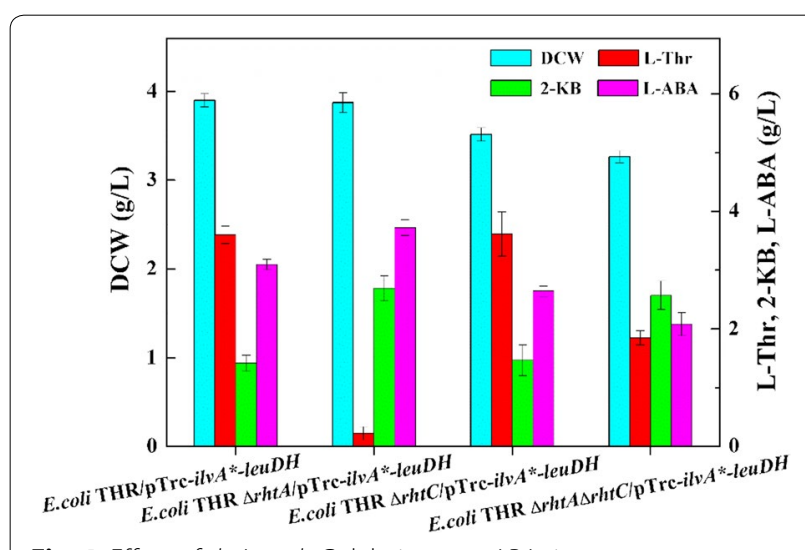

Fig. 4 Effect of rhtA or rhtC deletion on L-ABA titer concentration of L-ABA than the other two strains (Fig. 4). The deletion of $r h t A$ in the chromosome led to the increase of $\mathrm{L}-\mathrm{ABA}$ concentration from $3.09 \mathrm{~g} / \mathrm{L}$ to $3.72 \mathrm{~g} / \mathrm{L}$ and the remaining $\mathrm{L}$-threonine decrease from $3.47 \mathrm{~g} / \mathrm{L}$ to $0.22 \mathrm{~g} / \mathrm{L}$, which indicated that the modification of the L-threonine transport pathway is an efficient strategy for L-ABA improvement.

In addition, three acetohydroxy acid synthase (AHAS) isoenzymes that $E$. coli possessed, which show different biochemical properties and regulation mechanisms, play important roles in the biosynthesis of L-isoleucine. Among them, AHAS III, encoded by $i l v I H$, exhibites a much higher affinity for 2-KB [28] and AHAS I, encoded by ilvBN, displays a higher affinity for pyruvate than $2-\mathrm{KB}$ [28]. However, AHAS II, encoded by $i l v G M$, is not expressed due to the frameshift mutation of ilvG in $E$. coli [29]. Thus, only the gene $i l v I H$ from the E. coli THR $\Delta r h t$ A chromosome was knocked out to reduce the metabolic flux from 2-KB to L-isoleucine, the resulting strain E. coli THR $\Delta r h t \mathrm{~A} \Delta i l v I H / \mathrm{pTrc}-i l v A A^{*}-l e u D H$ was capable of producing $4.42 \mathrm{~g} / \mathrm{L} \mathrm{L-ABA}$ (Fig. 5).

\section{Regulation of the expression strength of ilv $A^{*}$ and leuDH via promoter alteration}

It was observed that $3.56 \mathrm{~g} / \mathrm{L} 2-\mathrm{KB}$ was remained in flask culture of $E$. coli THR $\Delta r h t \mathrm{~A} \Delta i l v I H / \mathrm{pTrc}-i l v A^{*}$ $l e u D H$. We reasoned that the uncoordinated expression of $i l v A^{*}$ and $l e u D H$ might account for the extracellular accumulation of $2-\mathrm{KB}$. Therefore, it is necessary to regulate the expression of $i l v A^{*}$ and $l e u D H$ via promoter alteration. We employed different promoters with different strengths, including Pbs [30], Trc and Gap from $E$. coli BL21 (DE3), to regulate the expression of $i l v A^{*}$ and leuDH based on plasmid pTrc-ilvA*-leuDH. To investigate the strengths of different promoters, enhanced green fluorescent protein (eGFP) was introduced and used as

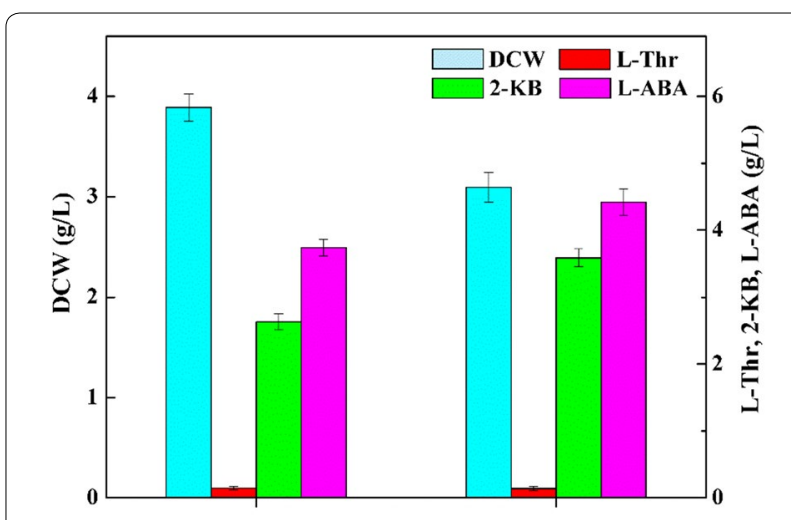

E.coli THR $\triangle r h t A / \mathrm{pT}$ rc-ilvA *-leuDH E.coli THR $\triangle r h t A \Delta i l v I H / \mathrm{pT}$ re-ilvA*-leuDH Fig. 5 Effect of ilvIH deletion on L-ABA titer 
a reporter. As a result, eGFP was successfully expressed under the control of three promoters, respectively in E. coli THR $\Delta r h t \mathrm{~A} \Delta i l v I H$ and the relative fluorescence intensity (au/OD600) from strong to weak was Pbs-eGFP, Trc-eGFP and Gap-eGFP (Fig. 6a). Twelve recombinant plasmids were constructed when three promoters were inserted or replaced before the $i l v A^{*}$ or $l e u D H$, respectively (Table 2). The results showed that $4.86 \mathrm{~g} / \mathrm{L}$ of L-ABA was produced by E. coli THR $\Delta r h t \mathrm{~A} \Delta i l v I H / \mathrm{Gap}-$ $i l v A^{*}$-Pbs-leuDH (Fig. 6b), which was the strain with the highest yield of L-ABA compared with other strains constructed in this study. Moreover, the accumulation of $2-\mathrm{KB}$ was decreased to $1.98 \mathrm{~g} / \mathrm{L}$, whereas the cell growth did not change remarkably.

\section{Fed-batch fermentation for L-ABA production}

As the platform strains for the production of L-ABA through rational metabolic engineering was successfully constructed, fed-batch fermentation was performed to evaluate the potential of the engineered strain $E$. coli THR $\Delta r h t A \Delta i l v I H / G a p-i l v A^{*}$-Pbs-leuDH. During the fermentation, the initially-fed glucose was exhausted at approximately $12 \mathrm{~h}$. When the glucose concentration in the broth was less than $5 \mathrm{~g} / \mathrm{L}$, feed medium was injected into the broth to raise the residual glucose concentration to around $20 \mathrm{~g} / \mathrm{L}$. Production of L-ABA presented a cell growth-dependent profile in the first $36 \mathrm{~h}$ of the fermentation. When the growth of the cells entered the stationary phase, L-ABA was continuously accumulated, but at a lower rate than that in the exponential phase, followed by a slight decrease in the titer after $48 \mathrm{~h}$ of the fermentation (Fig. 7). As a result, $9.33 \mathrm{~g} / \mathrm{L}$ of L-ABA was produced from glucose in a total $60 \mathrm{~h}$ of fed-batch fermentation, representing a 1.92-fold increase compared to the titer achieved in shake flask. Meanwhile, 2-KB was detected as the main byproduct during the fermentation in the $5 \mathrm{~L}$ bioreactor with the titer of $3.27 \mathrm{~g} / \mathrm{L}$. Another byproduct L-threonine was barely detected.

\section{Discussion}

In this study, we have developed a novel biosynthesis process for L-ABA production directly from glucose by fermentation using the genetically engineered $E$. coli strain. The results confirmed that the high expression level of leuDH and $i l v A^{*}$ successfully expanded the biosynthetic pathway, resulting in $3.60 \mathrm{~g} / \mathrm{L} \mathrm{L}$-threonine, $1.42 \mathrm{~g} / \mathrm{L} 2-\mathrm{KB}$ and $3.09 \mathrm{~g} / \mathrm{L} \mathrm{L}-\mathrm{ABA}$ in shake flask. Comparing to the traditional enzyme catalytic production method, this

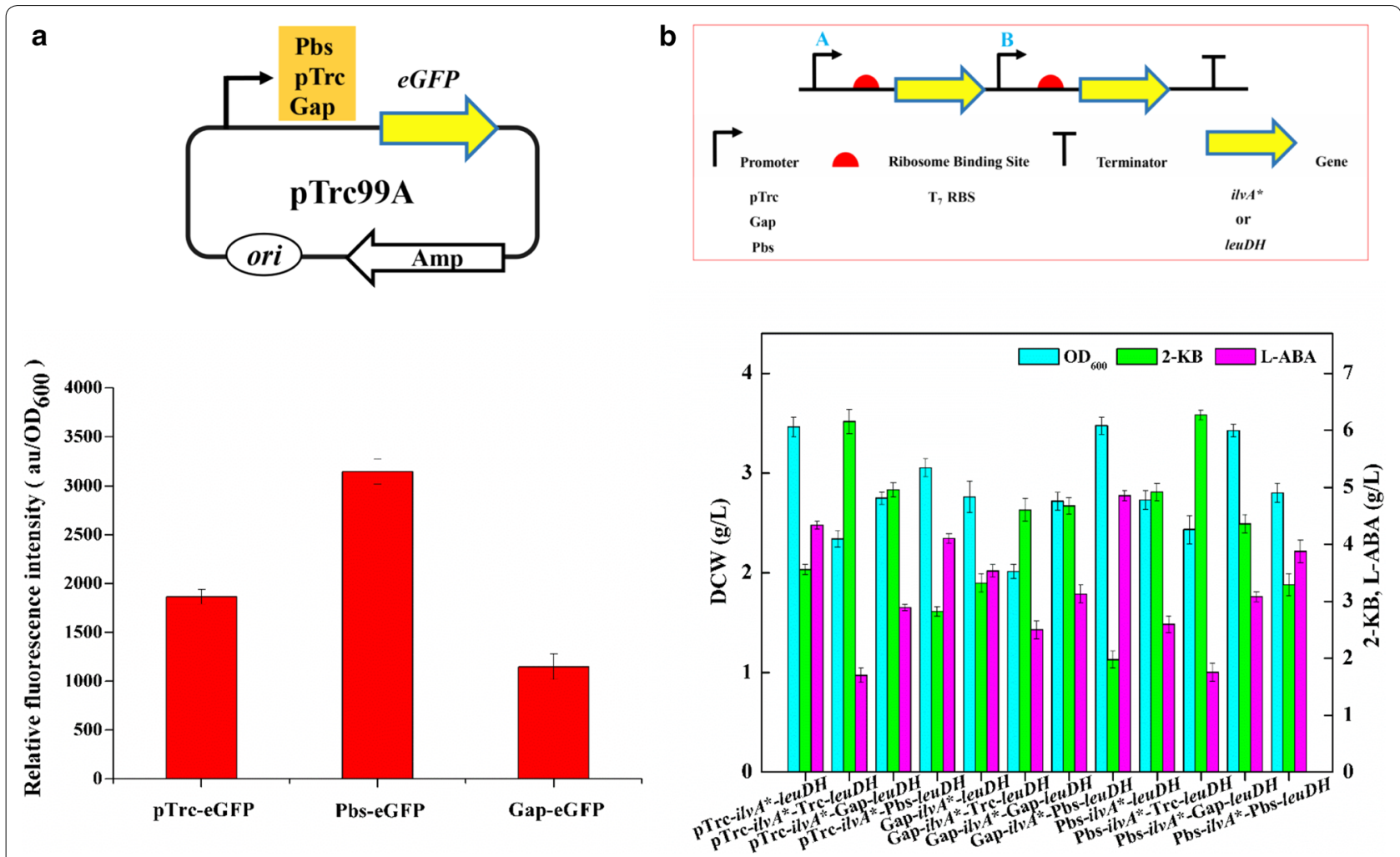

Fig. 6 Regulating the expression of ilvA* and leuDH for L-ABA titer. a Relative fluorescence intensity $\left(\mathrm{au} / \mathrm{OD}_{600}\right)$ of eGFP harbored in different promoters. $\mathbf{b}$ Effect of promoters with different strengths on L-ABA titer 
Table 2 Descriptions and sources of plasmids used in this study

\begin{tabular}{|c|c|c|}
\hline Plasmids & Description & Sources \\
\hline pTrc99a & AmpR, pBR322-origin, trc promoter, $4.2 \mathrm{~kb}$ & {$[35,38]$} \\
\hline pCas & $\mathrm{Kan}^{\mathrm{R}}$, Cas9 nuclease expression plasmid, temperature-sensitive origin & {$[39,40]$} \\
\hline pTrc-ilvA* & AmpR, ilvA* cloned in the sac I and BamH I site of pTrc99A & This study \\
\hline Gap-ilvA* & $A m p^{R}$, replacement of $\operatorname{Trc}$ promoter in pTrc-ilvA* with the Gap promoter & This study \\
\hline Pbs-ilvA* & $A m p^{R}$, replacement of $\operatorname{Trc}$ promoter in pTrc-ilvA* with the Pbs promoter & This study \\
\hline pTrc-ilvA*-BleuDH & Amp ${ }^{R}$, BleuDH cloned in the Xba I and Hind III site of pTrc-ilvA* & This study \\
\hline pTrc-ilvA*-leuDH & AmpR, leuDH cloned in the Xba I and Hind III site of pTrc-ilvA* & This study \\
\hline pTrc-ilvA*-Trc-leuDH & Amp ${ }^{R}$, leuDH carrying a Trc promoter and RBS cloned in the Xba I and Hind III site of pTrc-ilvA* & This study \\
\hline pTrc-ilvA*-Gap-leuDH & Amp ${ }^{R}$, leuDH carrying a Gap promoter and RBS cloned in the Xba I and Hind III site of pTrc-ilvA* & This study \\
\hline pTrc-ilvA*-Pbs-leuDH & Amp ${ }^{R}$, leuDH carrying a Pbs promoter and RBS cloned in the Xba I and Hind III site of pTrc-ilvA* & This study \\
\hline Gap-ilvA*-leuDH & $A m p^{R}$, replacement of Trc promoter in pTrc-ilvA*-leuDH with the Gap promoter & This study \\
\hline Gap-ilvA*-Trc-leuDH & Amp ${ }^{R}$, leuDH carrying a Trc promoter and RBS cloned in the Xba I and Hind III site of Gap-ilvA* & This study \\
\hline Gap-ilvA*-Gap-leuDH & $\mathrm{Amp}^{\mathrm{R}}$, leuDH carrying a Gap promoter and RBS cloned in the Xba I and Hind III site of Gap-ilvA* & This study \\
\hline Gap-ilvA*-Pbs-leuDH & Amp ${ }^{R}$, leuDH carrying a Pbs promoter and RBS cloned in the Xba I and Hind III site of Gap-ilvA* & This study \\
\hline Pbs-ilvA*-leuDH & Amp ${ }^{R}$, replacement of Trc promoter in pTrc-ilvA*-leuDH with the Pbs promoter & This study \\
\hline Pbs-ilvA*-Trc-leuDH & Amp ${ }^{R}$, leuDH carrying a Trc promoter and RBS cloned in the Xba I and Hind III site of Pbs-ilvA* & This study \\
\hline Pbs-ilvA*-Gap-leuDH & Amp ${ }^{R}$, leuDH carrying a Gap promoter and RBS cloned in the Xba I and Hind III site of Pbs-ilVA* & This study \\
\hline Pbs-ilvA*-Pbs-leuDH & $\mathrm{Amp}^{\mathrm{R}}$, leuDH carrying a Pbs promoter and RBS cloned in the Xba I and Hind III site of pbs-ilvA* & This study \\
\hline pTarget-X & $\begin{array}{l}\text { A plasmid used to transcript sgRNA targeting the particular gene } X \text { in genome. } X \text { refers to the amino acid } \\
\text { biosynthetic pathways }\end{array}$ & This study \\
\hline
\end{tabular}

Sp spectinomycin, Kan kanamycin, Amp ampicillin, $R$ resistance

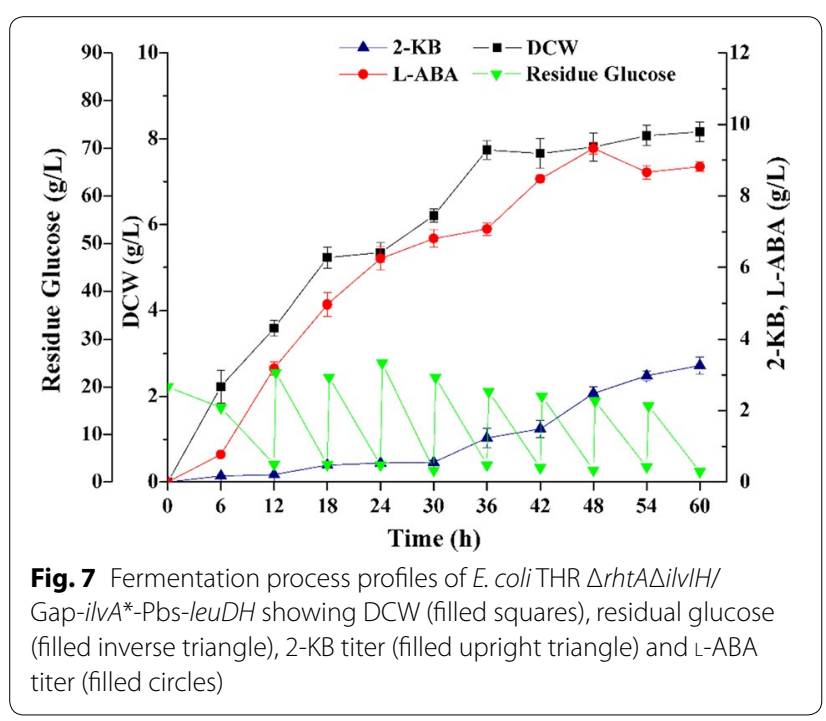

synthetic process possesses the advantages of simplicity in the production process and the production costssavings, which represents an attractive approach for the production of various valuable nonnatural products from inexpensive renewable resources.

To avoid the excessive accumulation of extracellular L-threonine, a partial inactivation of the L-threonine export system was employed. In accordance with the previous reports [21, 27], $r h t A$ and $r h t C$, which encoded strong L-threonine exporter, were deleted from the E. coli THR strain chromosome to inactivate the L-threonine export system. Our result indicated that it was better to knock out the $r h t A$ gene alone rather than to knock out the $r h t C$ gene alone or both genes at the same time regarding to the $\mathrm{L}-\mathrm{ABA}$ production. The rhtA-deletion strain E. coli THR $\Delta r h t \mathrm{~A} / \mathrm{p} T r c-i l v A^{*}$-leuDH showed an L-ABA production enhancement by $20.4 \%$ in comparison with that of E. coli THR/pTrc-ilvA*-leuDH. The results further indicated that the reasonable modification of L-threonine transport system was beneficial to the accumulation of L-ABA.

As competitive branches, the disruption of L-isoleucine biosynthetic pathways should be contributed to the improvement of L-ABA production [31]. Block of the L-isoleucine metabolic pathway by disrupting $i l v I H$ made the titer of L-ABA in E. coli THR $\Delta r h t A \Delta i l v I H /$ pTrc-ilv $A^{*}$-leuDH increased by 1.19 -fold compared to that in E. coli THR $\Delta r h t A /$ pTrc-ilvA*-leuDH, but the cell growth decreased. It is concluded that $i l v I H$ disruption allowed the diversion of 2-KB flowed to L-isoleucine to $\mathrm{L}-\mathrm{ABA}$, and therefore improved the titer of $\mathrm{L}-\mathrm{ABA}$, but caused accumulation of $2-\mathrm{KB}$ to the value of $3.56 \mathrm{~g} / \mathrm{L}$, which led to a reduction in cell growth [31]. Interestingly, the L-ABA titer was accumulated to $4.86 \mathrm{~g} / \mathrm{L}$ and $2-\mathrm{KB}$ decreased to $1.98 \mathrm{~g} / \mathrm{L}$ in E. coli $\mathrm{THR}$ 
$\Delta r h t A \Delta i l v I H / G a p-i l v A^{*}$-Pbs-leuDH without any obvious reduction of cell growth when promoters of different strengths including Pbs [30] and Gap from E. coli BL21 (DE3) were employed to regulate the expression of $i l v A^{*}$ and $l e u D H$. These results indicated that the disruption of $i l v I H$ drived more carbon flux to L-ABA and proper adjustments of attenuating the expression of $i l v A^{*}$ by a relatively weak promoter and enhancing the expression of leuDH by a strong promoter were also beneficial for the biosynthesis of L-ABA in this strain.

This work reported the development of a bacterial platform for enhanced production of a nonnatural amino acid L-ABA. The highest yield of L-ABA achieved by the engineered $E$. coli strain was $9.33 \mathrm{~g} / \mathrm{L}$ via fed-batch fermentation, indicating a great potential for large-scale production. However, there are still some bottlenecks, including the intracellular L-ABA transfer, plasmid elimination, metabolic burden and high costs of fermentation due to the large amount requirement of glucose and high concentration of L-methionine, L-isoleucine and L-lysine, waiting to be conquered for the industrial production of L-ABA. Therefore, screening of relevant genes encoding L-ABA exporter and integrating the involved genes into the chromosome of $E$. coli THR will be carried out in the future. In addition, the fermentation medium and condition will be further optimized to reduce the production costs and increase the $\mathrm{L}-\mathrm{ABA}$ titer.

\section{Conclusions}

In this study, a novel strain E. coli THR $\Delta r h t A \Delta i l v I H /$ Gap-ilvA*-Pbs-leuDH for L-ABA production was constructed through metabolic engineering. The $i l v A$ gene from E. coli W3110 and the leuDH gene from T. intermedius were firstly co-expressed in E. coli THR, and $3.09 \mathrm{~g} / \mathrm{L}$ of L-ABA was achieved. Then, the $r h t A$ gene was disrupted to decrease the extracellular secretion of $\mathrm{L}$-threonine and the titer of $\mathrm{L}$-ABA was improved to $3.72 \mathrm{~g} / \mathrm{L}$. To block the catabolism from $2-\mathrm{KB}$ to L-isoleucine, the $i l v I H$ gene was disrupted and the L-ABA titer was increased by $18.8 \%$ compared to the parental strain. Furthermore, in order to obtain a better expression of $i l v A$ and $l e u D H$, different promoters were, respectively inserted or replaced before the two enzymes to regulate their expression, resulting in L-ABA accumulation up to $4.86 \mathrm{~g} / \mathrm{L}$. Finally, L-ABA titer of the optimal strain $E$. coli THR $\Delta r h t A \Delta i l v I H / G a p-i l v A^{*}$-Pbs-leuDH reached to $9.33 \mathrm{~g} / \mathrm{L}$ in fed-batch fermentation. This study offers a possible approach for the industrial bioproduction of L-ABA and paves a way for the industrialization of other nonnatural amino acids.

\section{Methods}

Strains, media, and growth conditions

The bacterial strains used in this study were listed in Table 1. E. coli DH5 $\alpha$ was used as host for the recombinant plasmid. E. coli W3110 and its derivatives were applied to produce L-ABA.

TPM medium was used to monitor the production of L-ABA, during the growth of cells at $35{ }^{\circ} \mathrm{C}$. TPM medium contains per liter: glucose, 50 g; yeast extract, 6 g; $\mathrm{MgSO}_{4} \cdot 7 \mathrm{H}_{2} \mathrm{O}, 2 \mathrm{~g} ; \mathrm{KH}_{2} \mathrm{PO}_{4}, 4 \mathrm{~g}$; $\left(\mathrm{NH}_{4}\right)_{2} \mathrm{SO}_{4}, 14$ g; betaine, $1 \mathrm{~g}$; L-methionine, $0.149 \mathrm{~g}$; L-lysine, $0.164 \mathrm{~g}$; trace metal solution, $5 \mathrm{~mL}$ and $\mathrm{CaCO}_{3}, 30 \mathrm{~g}$. The trace metal solution contains per liter: $\mathrm{FeSO}_{4} \cdot 7 \mathrm{H}_{2} \mathrm{O}, 10 \mathrm{~g} ; \mathrm{CaCl}_{2}, 1.35 \mathrm{~g}$; $\mathrm{ZnSO}_{4} \cdot 7 \mathrm{H}_{2} \mathrm{O}, 2.25 \mathrm{~g} ; \mathrm{MnSO}_{4} \cdot 4 \mathrm{H}_{2} \mathrm{O}, 0.5 \mathrm{~g} ; \mathrm{CuSO}_{4} \cdot 5 \mathrm{H}_{2} \mathrm{O}$, $1 \mathrm{~g} ;\left(\mathrm{NH}_{4}\right)_{6} \mathrm{Mo}_{7} \mathrm{O}_{24} \cdot 4 \mathrm{H}_{2} \mathrm{O}, 0.106 \mathrm{~g} ; \mathrm{Na}_{2} \mathrm{~B}_{4} \mathrm{O}_{7} \cdot 10 \mathrm{H}_{2} \mathrm{O}, 0.23 \mathrm{~g}$; $35 \% \mathrm{HCl}, 10 \mathrm{~mL}$ [21]. The medium was adjusted to $\mathrm{pH}$ 7.0 by $\mathrm{KOH}$. Ampicillin (100 mg/L; Sangon, Shanghai, China), kanamycin (50 mg/L; Solarbio, Beijing, China), and isopropyl- $\beta$-D-thio-galactopyranoside (IPTG; $100 \mu \mathrm{M}$; Sangon, Shanghai, China) were added when necessary.

For precultivation of E. coli $\mathrm{W} 3110$ and its derivatives, a single clone was grown in $5 \mathrm{~mL}$ Luria-Bertani (LB) medium. After incubation for $10 \mathrm{~h}$, the seed culture was inoculated into $500 \mathrm{~mL}$ shake flask containing $30 \mathrm{~mL}$ cultivation media. Cells were grown at $35{ }^{\circ} \mathrm{C}$ and $100 \mathrm{mg} / \mathrm{L}$ ampicillin was supplemented when needed. For L-methionine auxotrophic and L-lysine auxotrophic mutants, L-methionine and L-lysine with final concentrations of $0.149 \mathrm{~g} / \mathrm{L}$ and $0.164 \mathrm{~g} / \mathrm{L}$ were added, respectively in fermentation broth to fairly compare their titer with others trains [32]. A final concentration of $0.1 \mathrm{mM}$ IPTG was added to the medium for gene induction when the optical density at $600 \mathrm{~nm}\left(\mathrm{OD}_{600}\right)$ reached of 0.4-0.6. Fermentation of strains were conducted simultaneously under the same culture conditions for at least three times.

\section{Construction of co-expression plasmids}

All plasmids used in this study were listed in Table 2. The primers used for gene amplification and recombinant plasmid construction were listed in Additional file 1: Table S1. In general, genes including $i l v A$ encoding feedback-resistant threonine dehydratase and leuDH encoding L-leucine dehydrogenase from Thermoactinomyces intermedius were overexpressed in a plasmid-based manner. The procedures of recombinant plasmid construction were described in detail shown in Additional file 1: Figure S1.

\section{Genomic engineering: promoter replacement, site-directed mutagenesis and chromosomal gene knock-out}

Donor dsDNA with 500-bp homologous arms on each side was designed based on the sequence of the gene cluster and the location of sgRNA. Two homologous 
arms and the Trc promoter were separately amplified and fused together by overlap-extension PCR. The PCR products were purified by gel extraction prior to electroporation. Electrocompetent cells were prepared according to a previous report [33]. A single colony was transferred into $5 \mathrm{~mL}$ of LB medium containing $50 \mathrm{mg} / \mathrm{L}$ kanamycin and $10 \mathrm{mM}$ L-arabinose (Aladdin, Shanghai, China), and was grown at $30{ }^{\circ} \mathrm{C}$ overnight. An aliquot consisted of $100 \mu \mathrm{L}$ resulting preculture was transferred into $50 \mathrm{~mL}$ of LB medium containing $50 \mathrm{mg} / \mathrm{L}$ kanamycin and $10 \mathrm{mM}$ $\mathrm{L}$-arabinose, and was grown at $30{ }^{\circ} \mathrm{C}$ to an $\mathrm{OD}_{600}$ value of 0.4-0.6. The cultures were chilled in ice-water slurry for $15 \mathrm{~min}$, harvested by centrifugation at $4000 \times g$ for $10 \mathrm{~min}$, and washed twice with ice-cold sterile $\mathrm{dd}_{2} \mathrm{O}$. Subsequently, $200 \mu \mathrm{L}$ of ice-cold sterile glycerol $(10 \%$, $\mathrm{v} / \mathrm{v}$ ) was used to re-suspend the cells, and the glycerol suspension was separated into $100 \mu \mathrm{L}$ aliquots for each reaction. Donor dsDNA (400 ng) and the corresponding pTarget plasmid (100 ng) were added to each electroporation reaction. A Bio-Rad MicroPulser (Bio-Rad, Hercules, CA, USA) was used for electroporation $(0.1 \mathrm{~cm}$ cuvette, $1.8 \mathrm{kV}$ ). $1 \mathrm{~mL}$ of pre-chilled LB medium was added to the cuvette and the resulting cell suspension was transferred into a tube within $1 \mathrm{~min}$. The culture was then regenerated at $30{ }^{\circ} \mathrm{C}$ for $2 \mathrm{~h}$ prior to plating. Positive colonies were transferred into LB medium containing $0.5 \mathrm{mM}$ IPTG and cultivated at $30{ }^{\circ} \mathrm{C}$ for $8-10 \mathrm{~h}$ to eliminate the pTarget plasmid. The pCas plasmid was cured by cultivating at $37^{\circ} \mathrm{C}$ overnight. The cultures after plasmid curing were streaked, and the colonies were tested for kanamycin $(50 \mathrm{mg} / \mathrm{L})$ and spectinomycin $(50 \mathrm{mg} / \mathrm{L}$; Sangon, Shanghai, China) sensitivity, and were confirmed by sequencing $[19,34]$.

\section{Fermentation}

For fed-batch fermentation, a $150 \mathrm{~mL}$ seed cultured in LB medium for $12 \mathrm{~h}$ was inoculated into a $5 \mathrm{~L}$ agitated bioreactor (Shanghai Baoxing biological equipment Engineering Co. Ltd, China) with $3 \mathrm{~L}$ TPM medium equipped with dissolved oxygen, $\mathrm{pH}$ and temperature probes. Cells were incubated at $35{ }^{\circ} \mathrm{C}$ with agitation at $500 \mathrm{rpm}$ and $2 \mathrm{~L} /$ min external air flow. Ammonia or phosphate was automatically fed into the broth to keep the $\mathrm{pH}$ at 7.0. When the glucose concentration in the broth was less than $5 \mathrm{~g} / \mathrm{L}, 100 \mathrm{~mL}$ of feed solution $(500 \mathrm{~g} / \mathrm{L}$ glucose, $14 \mathrm{~g} / \mathrm{L}$ $\left(\mathrm{NH}_{4}\right)_{2} \mathrm{SO}_{4}, 12.5 \mathrm{~g} / \mathrm{L} \mathrm{KH} \mathrm{KO}_{4}, 3 \mathrm{~g} / \mathrm{L}$ L-methionine and $4.4 \mathrm{~g} / \mathrm{L} \mathrm{L}$-lysine) was injected into the broth to raise the residual glucose concentration to around $20 \mathrm{~g} / \mathrm{L}[21,35]$.

\section{Analytical methods}

The cell concentration was monitored by measuring the absorbance at $600 \mathrm{~nm}$ which was then converted to Dry Cell Weight (DCW) by a calibration curve [36].
The fermentation supernatants were filtered through a $0.22 \mu \mathrm{m}$ syringe filter (Nylon66; Jinteng, Tianjin, China) and used for determination of residual glucose, amino acids and organic acids. The concentration of $2-\mathrm{KB}$ in the culture was determined by high pressure liquid chromatography (HPLC, Waters, Milford, MA, USA) using an Aminex HPX-87H column $(7.8 \times 300 \mathrm{~mm}$, Bio-Rad, Hercules, CA, USA) under the following conditions: mobile phase $5 \mathrm{mM} \mathrm{H}_{2} \mathrm{SO}_{4}$; flow rate $0.5 \mathrm{~mL} / \mathrm{min}$; column temperature $30{ }^{\circ} \mathrm{C}$; UV absorption $215 \mathrm{~nm}$ [31]. The residual concentration of glucose in the media was measured using a glucose analyzer (YSI model 2300, Xylem Inc., Rye Brook, NY, USA) [37] and the amino acids were determined using an amino acid analyzer (SYKAMS-433D, SYKAM, Munich, Germany). The LThr and L-ABA were derivatized with DNFB/Acetonitrile $(\mathrm{DNFB}=1 \%$, acetonitrile $=99 \%)$ and analyzed by HPLC using a LC-18DB column $(5 \mu \mathrm{m}, 4.6 \times 250 \mathrm{~mm}$, Agilent, Beijing, China). Derivatization method: $100 \mu \mathrm{L}$ of the fermentation supernatants diluted 10 times with $\mathrm{dd}_{2} \mathrm{O}$ were added to a $1.5 \mathrm{~mL}$ centrifuge tube, and then $50 \mu \mathrm{L}$ of DNFB/Acetonitrile buffer and $100 \mu \mathrm{L}$ of $0.5 \mathrm{~mol} / \mathrm{L}$ $\mathrm{NaHCO}_{3}$ buffer were added. The reaction solution was placed in a dark water bath at $60^{\circ} \mathrm{C}$ for $1 \mathrm{~h}$. After the reaction was completed, $750 \mu \mathrm{L}$ of $0.2 \mathrm{~mol} / \mathrm{L}$ phosphate buffer at $\mathrm{pH} 7.0$ was added. Finally, the reaction solution was filtered through a $0.22 \mu \mathrm{m}$ syringe filter. The gradient elution profile, at $1 \mathrm{~mL} / \mathrm{min}$, was as follows: $16 \% \mathrm{~A}$ and $84 \% \mathrm{~B}$ at $0-0.18 \mathrm{~min}, 30 \% \mathrm{~A}$ and $70 \%$ $\mathrm{B}$ at $0.18-2.4 \mathrm{~min}, 34 \% \mathrm{~A}$ and $66 \% \mathrm{~B}$ at $2.4-4.2 \mathrm{~min}, 43 \%$ $\mathrm{A}$ and $57 \% \mathrm{~B}$ at $4.2-7.2 \mathrm{~min}, 55 \% \mathrm{~A}$ and $45 \% \mathrm{~B}$ at $7.2-$ $13.3 \mathrm{~min}, 55 \% \mathrm{~A}$ and $45 \% \mathrm{~B}$ at $13.3-15 \mathrm{~min}, 98 \% \mathrm{~A}$ and $2 \% \mathrm{~B}$ at $15-20.4 \mathrm{~min}, 16 \% \mathrm{~A}$ and $84 \% \mathrm{~B}$ at $20.4-21.3 \mathrm{~min}$, $16 \% \mathrm{~A}$ and $84 \% \mathrm{~B}$ at $21.3-30 \mathrm{~min}(\mathrm{~A}=50 \%$ acetonitrile; $\mathrm{B}=4.1 \mathrm{~g} / \mathrm{L}$ sodium acetate, $\mathrm{pH}$ adjustment to the value of 6.4 with acetic acid); column temperature $33{ }^{\circ} \mathrm{C}$; UV absorption at $360 \mathrm{~nm}$. The retention time of the main peak of the solution should be consistent with that of the reference solution. The undiluted medium and fermentation broth of $E$. coli W3110/pTrc99A were used as negative controls. Amino acid standards were purchased from Sykam (Amino Acid Calibration Solution H, Sykam, Germany).

\section{Statistical analysis}

Unless otherwise specified, all experiments in this study were performed in triplicates. An analysis of variance (ANOVA) was carried out using the SAS program version 8.1 (SAS Institute Inc., Cary, NC, USA). The least significant difference (LSD) was computed at $p<0.05$. All figures were drawn using Origin software version 8.5 (Origin Lab Corp., Northampton, MA, USA). Error bars denote standard deviation of the mean. 


\section{Additional file}

Additional file 1: Table S1. Primers for donor DNA amplification, pTarget construction and positive colony validation. Figure S1. Structures of plasmids used in this study. Detailed description on constructions of these plasmids is shown in the section.

\section{Abbreviations}

L-ABA: L-2-aminobutyric acid; 2-KB: 2-ketobutyrate; DCW: dry cell weight; IPTG: isopropyl $\beta$-d-1-thiogalactopyranoside; L-Thr: L-threonine; eGFP: enhanced green fluorescent protein.

\section{Authors' contributions}

$J M X, J Q L, Z B, Z Q L$ and YGZ designed the study. JQL and JMX carried out the bulk of the experiments. JMX, JQL, ZB, ZQL and YGZ analyzed and interpreted the data. JQL and ZQL wrote the manuscript. All authors read and approved the final manuscript.

\section{Acknowledgements}

Not applicable.

\section{Competing interests}

The authors declare that they have no competing interests.

\section{Availability of data and materials}

Sequences data used in this study have been deposited in the GenBank with accession number AP009048 for the gene of ilvA from Escherichia coli W3110, AE016877 for the gene of BleuDH from Bacillus cereus and X79068.1 for the gene of leuDH from Thermoactinomyces intermedius.

\section{Consent for publication}

Not applicable.

Ethics approval and consent to participate Not applicable.

\section{Funding}

This work was financially supported by Zhejiang Provincial Public Welfare Technology Application Research Projects (2017C33157), the National Natural Science Foundation of China (No. 31500031), and the Natural Science Foundation of Zhejiang Province (No. LQ14B060004).

\section{Publisher's Note}

Springer Nature remains neutral with regard to jurisdictional claims in published maps and institutional affiliations.

Received: 3 January 2019 Accepted: 25 February 2019

Published online: 28 February 2019

\section{References}

1. Shin JS, Kim BG. Transaminase-catalyzed asymmetric synthesis of L-2-aminobutyric acid from achiral reactants. Biotechnol Lett. 2009;31(10):1595-9.

2. Taylor PP, Pantaleone DP, Senkpeil RF, Fotheringham IG. Novel biosynthetic approaches to the production of unnatural amino acids using transaminases. Trends Biotechnol. 1998;16(10):412-8.

3. Zhu L, Tao R, Wang Y, Jiang $Y$, Lin $X$, Yang $Y$, Zheng H, Jiang W, Yang $S$. Removal of L-alanine from the production of $L$-2-aminobutyric acid by introduction of alanine racemase and D-amino acid oxidase. Appl Microbiol Biotechnol. 2011;90(3):903-10.

4. Ragonese R, Macka M, Hughes J, Petocz P. The use of the Box-Behnken experimental design in the optimisation and robustness testing of a capillary electrophoresis method for the analysis of ethambutol hydrochloride in a pharmaceutical formulation. Biomed Anal. 2002;27(6):995-7.

5. Jeffery $E$, Meisters A. Electrochemical synthesis of amino acids by reductive amination of keto acids. I. Reduction at mercury electrodes. Aust J Chem. 1978:31(1):73-8.

6. Babievskii KK, Belikov VM, Tikhonova NA. Amino acids. Communication. 1 synthesis of DL-threonine and DL-2-aminobutyric acid based on condensations of nitroacetic ester. Bull Acad Sci USSR Div Chem Sci. 1965:14(1):76-81.

7. Fujii C, Yasui M, Ishimathu Y. Process for production of (+)-2-amino-1-butanol. US Patent. 3,979,457, 07 Sept 1976.

8. An Z, Gu X, Liu Y, Ge J, Zhu Q. Bioproduction of L-2-aminobutyric acid by a newly-isolated strain of Aspergillus tamarii ZJUT ZQ013. Catal Lett. 2017;147(4):837-44.

9. Liu ZQ, Lu MM, Zhang XH, Cheng F, Xu JM, Xue YP, Jin LQ, Wang YS, Zheng YG. Significant improvement of the nitrilase activity by semi-rational protein engineering and its application in the production of iminodiacetic acid. Int J Biol Macromol. 2018;116:563-71.

10. Liu ZQ, Wu L, Zhang XJ, Xue YP, Zheng YG. Directed evolution of carbonyl reductase from Rhodosporidium toruloides and its application in stereoselective synthesis of tert-butyl (3R,5S)-6-Chloro-3,5-dihydroxyhexanoate. J Agric Food Chem. 2017;65(18):3721-9.

11. Liu ZQ, Dong SC, Yin HH, Xue YP, Tang XL, Zhang XJ, He JY, Zheng YG. Enzymatic synthesis of an ezetimibe intermediate using carbonyl reductase coupled with glucose dehydrogenase in an aqueous-organic solvent system. Bioresour Technol. 2017;229:26-32.

12. Liu ZQ, Wu L, Zheng L, Wang WZ, Zhang XJ, Jin LQ, Zheng YG. Biosynthesis of tert-butyl (3R,5S)-6-chloro-3,5-dihydroxyhexanoate by carbonyl reductase from Rhodosporidium toruloides in mono and biphasic media. Bioresour Technol. 2018;249:161-7.

13. Zheng YG, Yin HH, Yu DF, Chen X, Tang XL, Zhang XJ, Xue YP, Wang YJ, Liu $Z Q$. Recent advances in biotechnological applications of alcohol dehydrogenases. Appl Microbiol Biotechnol. 2017;101(3):987-1001.

14. Fotheringham IG, Grinter N, Pantaleone DP, Senkpeil RF, Taylor PP. Engineering of a novel biochemical pathway for the biosynthesis of L-2-aminobutyric acid in Escherichia coli K12. Bioorg Med Chem. 1999;7(10):2209-13

15. Xu JM, Cheng F, Fu FT, Hu HF, Zheng YG. Semi-rational engineering of leucine dehydrogenase for L-2-aminobutyric acid production. Appl Biochem Biotechnol. 2017:182(3):898-909.

16. Zhang KC, Li H, Cho KM, Liao JC. Expanding metabolism for total biosynthesis of the nonnatural amino acid L-homoalanine. Proc Natl Acad Sci. 2010;107(14):6234-9.

17. Park JH, Lee SY. Metabolic pathways and fermentative production of L-aspartate family amino acids. Biotechnol J. 2010;5(6):560-77.

18. Leuchtenberger W, Huthmacher K, Drauz K. Biotechnological production of amino acids and derivatives: current status and prospects. Appl Microbiol Biotechnol. 2005;69(1):1-8.

19. Li YF, Lin ZQ, Huang C, Zhang Y, Wang ZW, Tang YJ, Chen T, Zhao XM. Metabolic engineering of Escherichia coli using CRISPR-Cas9 meditated genome editing. Metab Eng. 2015;31:13-21.

20. Zhang YF, Meng QL, Ma HW, Liu YF, Cao GQ, Zhang XR, Zheng P, Sun JB, Zhang DW, Jiang WX, Ma YH. Determination of key enzymes for threonine synthesis through in vitro metabolic pathway analysis. Microb Cell Fact. 2015:14:86.

21. Lee KH, Park JH, Kim TY, Kim HU, Lee SY. Systems metabolic engineering of Escherichia coli for L-threonine production. Mol Syst Biol. 2007;3(1):149.

22. Chen L, Chen Z, Zheng P, Sun JB, Zeng AP. Study and reengineering of the binding sites and allosteric regulation of biosynthetic threonine deaminase by isoleucine and valine in Escherichia coli. Appl Microbiol Biotechnol. 2013;97(7):2939-49.

23. Galkin A, Kulakova L, Yoshimura T, Soda K, Esaki N. Synthesis of optically active amino acids from alpha-keto acids with Escherichia coli cells expressing heterologous genes. Appl Environ Microbiol. 1997;63:4651-6.

24. Ansorge MB, Kula MR. Production of recombinant L-leucine dehydrogenase from Bacillus cereus in pilot scale using the runaway replication system E. coli [piet98]. Biotechnol Bioeng. 2000;68(5):557-62.

25. Livshits VA, Zakataeva NP, Aleshin VV, Vitushkina MV. Identification and characterization of the new gene $r$ th involved in threonine and homoserine efflux in Escherichia coli. Res Microbiol. 2003;154(2):123-35. 
26. Zakataeva NP, Aleshin WV, Tokmakova IL, Troshin PV, Livshits VA. The novel transmembrane Escherichia coli proteins involved in the amino acid efflux. FEBS Lett. 1999:452(3):228-32.

27. Lee JH, Sung BH, Kim MS, Blattner FR, Yoon BH, Kim JH, Kim SC. Metabolic engineering of a reduced-genome strain of Escherichia coli for L-threonine production. Microb Cell Fact. 2009;8:2.

28. Barak Z, Chipman DM, Gollop N. Physiological implications of the specificity of acetohydroxy acid synthase isozymes of enteric bacteria. J Bacteriol. 1987;169(8):3750-6.

29. Lawther RP, Calhoun DH, Adams CW, Hauser CA, Gray J, Hatfield GW. Molecular basis of valine resistance in Escherichia coli K-12. Proc Natl Acad Sci. 1981;78(2):922-5.

30. Yang S, Liu QT, Zhang YF, Du GC, Chen J, Kang Z. Construction and characterization of broad-spectrum promoters for synthetic biology. ACS Synth Biol. 2018;7(1):287-91.

31. Zhang CL, Qi JS, Li YJ, Fan XG, Xu QY, Chen N, Xie XX. Production of a-ketobutyrate using engineered Escherichia coli via temperature shift. Biotechnol Bioeng. 2016;113(9):2054-9.

32. Usuda Y, Kurahashi O. Effects of deregulation of methionine biosynthesis on methionine excretion in Escherichia coli. Appl Environ Microbiol. 2005;71:3228-34.

33. Li N, Zhang B, Wang ZW, Tang YJ, Chen T, Zhao XM. Engineering Escherichia coli for fumaric acid production from glycerol. Bioresour Technol. 2014;174:81-7.
34. Jiang Y, Chen B, Duan CL, Sun BB, Yang JJ, Yang S. Multigene editing in the Escherichia coli genome via the CRISPR-Cas9 system. Appl Environ Microbiol. 2015;81:2506-14

35. Huang JF, Liu ZQ, Jin LQ, Tang XL, Shen ZY, Yin HH, Zheng YG. Metabolic engineering of Escherichia coli for microbial production of L-methionine. Biotechnol Bioeng. 2017;114(4):843-51.

36. Peng LF, Shimizu K. Effect of fadR gene knockout on the metabolism of Escherichia coli based on analyses of protein expressions, enzyme activities and intracellular metabolite concentrations. Enzyme Microb Technol. 2006;38(3-4):512-20.

37. Fallet $C$, Rohe P, Franco-Lara E. Process optimization of the integrated synthesis and secretion of ectoine and hydroxyectoine under hyper/ hypo-osmotic stress. Biotechnol Bioeng. 2010;107(1):124-33.

38. Huang JF, Zhang B, Shen ZY, Liu ZQ, Zheng YG. Metabolic engineering of E. coli for the production of O-succinyl-L-homoserine with high yield. 3 Biotech. 2018;8:310.

39. Jiang Y, Chen B, Duan C, Sun B, Yang J, Yang S. Multigene editing in the Escherichia coli genome via the CRISPR-Cas9 system. Appl Environ Microbiol. 2015;81(7):2506-14.

40. Huang JF, Shen ZY, Mao QL, Zhang XM, Zhang B, Wu JS, Liu ZQ, Zheng YG. Systematic analysis of bottlenecks in a multi-branched and multilevel regulated pathway: the molecular fundamentals of L-methionine biosynthesis in Escherichia coli. ACS Synth Biol. 2018;7:2577-89.
Ready to submit your research? Choose BMC and benefit from:

- fast, convenient online submission

- thorough peer review by experienced researchers in your field

- rapid publication on acceptance

- support for research data, including large and complex data types

- gold Open Access which fosters wider collaboration and increased citations

- maximum visibility for your research: over 100M website views per year

At BMC, research is always in progress.

Learn more biomedcentral.com/submissions 